\title{
Abdominal Obesity among Outpatients in a Tertiary Level Eye ENT Hospital: A Descriptive Cross-sectional Study
}

\author{
Madan Prasad Upadhyay, ${ }^{2}$ Sanjib Kumar Upadhyay, ${ }^{1}$ Janak Raj Bhattarai, ${ }^{2}$ Bijay Khatri, ${ }^{2}$ \\ Rajan Shrestha ${ }^{2}$ \\ 'BP Eye Foundation, Hospital for Children Eye ENT and Rehabilitation Services, Bhaktapur, Nepal, ${ }^{2}$ Academic \\ and Research Department, BP Eye Foundation, Hospital for Children, Eye, ENT and Rehabilitation Services, \\ Bhaktapur, Nepal.
}

\section{ABSTRACT}

Introduction: Abdominal obesity, as abnormal fat accumulation that presents a risk to health, is a global epidemic. There is evidence to support a trait of abdominal adipose deposition despite normal body mass index in south asian populations with greater cardiometabolic risks. Thus, this study aimed to find out the prevalence of abdominal obesity using the waist to height ratio among outpatients in a tertiary level hospital.

Methods: This descriptive cross-sectional study was conducted among outpatients at a tertiary level hospital in Nepal from January 2016 to December 2018. Ethical approval was taken from the Ethical Review Board of Nepal Health Research Council (Reference no. 207/2019). Convenience sampling was done. The data were entered into excel and analyzed using Statistical Package for Social Sciences version 24 . Point estimate at $99 \%$ confidence interval was calculated along with frequency and proportion for binary data.

Results: Among 25,511 participants, 21,834 (85.6\%) (85.0-86.2 at 99\% Confidence Interval) participants had abdominal obesity using Waist-to-Height Ratio, higher in women 12,397 (86.4\%) than men 9,437 $(84.5 \%)$. The mean age of the participants was $53.37 \pm 13.15$ years and more than half $17,075(55.7 \%)$ of all participants were female.

Conclusions: The prevalence of abdominal obesity among hospital outpatients is higher than in other community-based studies. As hospitals attract large crowds and provide excellent opportunities for screening patients, their attendants, as well as providing opportunities for health promotion, we recommend the introduction of opportunistic obesity screening in all health facilities using weight to height ratio in a phased manner.

\section{Keywords: hospital; Nepal; obesity; outpatient; screening.}

\section{INTRODUCTION}

Abdominal obesity, abnormal or excessive fat accumulation that presents a risk to health, has become a global epidemic. ${ }^{1}$ The world is rapidly becoming obese. ${ }^{2,3}$ According to World Health Organization, the obesity rates have tripled since 1975. In 2016 more than 1.9 billion adults above 17 years were overweight and of those, over 650 million were obese. ${ }^{4,5}$ Nepal is following a similar trajectory ${ }^{6-10}$ as the country is rapidly undergoing urbanization, change in lifestyle, and dietary pattern. ${ }^{6,11}$
Based on the global burden of disease data, the cause of death from Non-communicable diseases (NCDs) in Nepal has reached $62 \%$ in 2017 from $36.1 \%$ in 2009. ${ }^{12,13}$ Measurement for Obesity among hospital outpatients is not a standard practice in most Low-and MiddleIncome countries including Nepal.

This study aimed to find out the prevalence of

Correspondence: Mr. Rajan Shrestha, BP Eye Foundation, Hospital for Children, Eye, ENT and Rehabilitation Services, Bhaktapur, Nepal. Email: rajanshrestha011@gmail.com, Phone: $+977-9860916172$. 
abdominal obesity using the Waist-to-Height Ratio (WHtR) among outpatients in a tertiary level hospital.

\section{METHODS}

This hospital-based descriptive cross-sectional study was conducted from January 2016 to December 2018 at Hospital for Children, Eye, ENT, and Rehabilitation Services (CHEERS), Bhaktapur, Nepal. Ethical approval was taken from the Ethical Review Board of Nepal Health Research Council (Reference no. 207/2019). Records of outpatients aged 35 years and above visiting the free Health Promotion and Screening service of CHEERS were reviewed. Pregnant women and people unable to stand properly were excluded from the analysis. Convenience sampling was done, and the sample size was calculated using the formula,

$$
\begin{aligned}
\mathrm{n} & =\mathrm{Z}^{2} \times(\mathrm{p} \times \mathrm{q}) / \mathrm{e}^{2} \\
& =(2.576)^{2} \times 0.5 \times(1-0.5) /(0.01)^{2} \\
& =16,590
\end{aligned}
$$

where,

$\mathrm{n}=$ required sample size

$\mathrm{Z}=2.576$, at $99 \%$ Confidence Interval (Cl)

$\mathrm{p}=$ prevalence of abdominal obesity using the waist to height ratio among outpatients in a tertiary level hospital taken as $50 \%$ for maximum sample size

$\mathrm{e}=1 \%$, margin of error

The calculated sample size was 16,590 . Adding a $20 \%$ non-response rate, the final calculated sample size was 20,737. However, records of 25,511 outpatients were included in the study.

Waist-to-Height Ratio ${ }^{14}$ (WHtR) 0.5 was considered as cut-off for abdominal obesity. Data entry was done in Excel (MS Office 2010). Data analysis was done in IBM Statistical Package for Social Sciences (version 24). Point estimate at $99 \% \mathrm{Cl}$ was calculated along with number and percentage. Continuous variables are shown as the mean \pm standard deviation (SD).

\section{RESULTS}

Among 25,511 participants, 21,834 (85.6\%) (85.0-86.2 at $99 \%$ Confidence Interval) participants had abdominal obesity. Abdominal Obesity was found higher in women 12,397 (86.4\%) than men 9,437 (84.5\%) (Table $1)$.

\begin{tabular}{|llll|}
\hline \multicolumn{3}{l}{ Table 1. Classification of Waist-to-Height Ratio } \\
(n=25,511).
\end{tabular}

The highest proportion of obesity was found in the age group $45-54$ years, in both male 2,741 (87.3\%) and female $3,414(88.4 \%)$. The next highest group was participants from age group 55-64 years in both male

$1,857(86.1 \%)$ and female 2,320 (86.6). The prevalence

\begin{tabular}{|c|c|c|c|c|}
\hline $\begin{array}{l}\text { Table } 2 \\
\text { group } 1\end{array}$ & $\begin{array}{l}\text { he p } \\
25,5\end{array}$ & ortion of & sity acc & to \\
\hline & & $\begin{array}{l}\geq 0.5 \\
\text { n (\%) }\end{array}$ & $<0.5$ & Total \\
\hline Male & $35-44$ & 3,004 (83.9) & $576(16.1)$ & 3580 \\
\hline & $45-54$ & $2,741(87.3)$ & $399(12.7)$ & 3140 \\
\hline & $55-64$ & $1,857(86.1)$ & 301 (13.9) & 2158 \\
\hline & $65-74$ & $1,167(82.4)$ & $249(17.6)$ & 1416 \\
\hline & $\begin{array}{l}75 \& \\
\text { above }\end{array}$ & $668(76.3)$ & $208(23.7$ & 876 \\
\hline Female & $35-44$ & 4,477 (88.0) & $613(12.9)$ & 5090 \\
\hline & $45-54$ & $3,414(88.4)$ & 449 (11.6) & 3863 \\
\hline & $55-64$ & $2,320(86.6)$ & $359(13.4)$ & 2679 \\
\hline & $65-74$ & $1,516(81.7)$ & $340(13.4)$ & 1856 \\
\hline & $\begin{array}{l}75 \& \\
\text { above }\end{array}$ & $670(78.5)$ & $183(21.5)$ & 853 \\
\hline
\end{tabular}
of abdominal obesity gradually decreased as age increased (Table 2).

Most of the participants were female 14,341 (56.2\%). Regardless of gender, the highest number of participants were from the age group 35 to 44 years

(32.1\% male, $35.5 \%$ female) and their numbers gradually decreased as the age increased (Table 3 ).

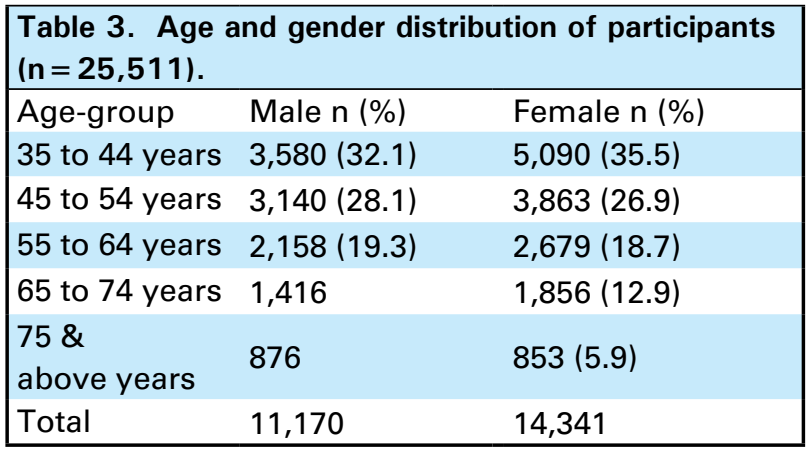

The mean (SD) age of male participants was $53.37 \pm 13.15$ years and $52.41 \pm 12.77$ years for female participants. The mean (SD) WC of males was $91.55 \pm 10.32 \mathrm{~cm}$ and females were $87.56 \pm 11.03 \mathrm{~cm}$. Similarly, mean $\mathrm{WHtR}$ was $0.56 \pm 0.06,0.58 \pm 0.07$ for males and females respectively (Table 4 ).

Table 4. Distribution of mean and SD for different variables $(n=25,511)$.

\begin{tabular}{|lll|}
\hline Variables & Male & Female \\
& Mean \pm SD & Mean \pm SD \\
Age (years) & $53.37 \pm 13.15$ & $52.41 \pm 12.77$ \\
Height $(\mathrm{cm})$ & $163.61 \pm 7.44$ & $151.54 \pm 6.75$ \\
\hline
\end{tabular}


Shrestha et al. Abdominal Obesity among Outpatients in a Tertiary Level Eye ENT Hospital: A Descriptive Cross-sectional study

\begin{tabular}{|lcc|}
\hline $\begin{array}{l}\text { Waist Circumference } \\
\text { (CM) }\end{array}$ & $91.55 \pm 10.32$ & $87.56 \pm 11.03$ \\
Waist to Height Ratio & $0.56 \pm 0.06$ & $0.58 \pm 0.07$ \\
\hline
\end{tabular}

\section{DISCUSSION}

This study analyzed the Waist-to-Height ratio of a large number of participants $(25,511)$ visiting the free Health Promotion and Screening service of CHEERS in 3 year period. We choose Waist-to-Height ratio as the measure of abdominal obesity for this study as it has been shown to be a superior proxy than other obesity metrics for assessing the long-term risk of NCDs. ${ }^{15-17}$ There is an increasing body of evidence to support a trait of abdominal adipose deposition despite normal weight in South Asian populations. ${ }^{18-21}$ Besides the importance of abdominal obesity, very few studies measured abdominal obesity, almost all studies were community-based except a study done in India in outpatients ${ }^{22}$ which used Waist circumference and Waist-to-Hip ratio as obesity measurement and, none from Nepal hospitals.

In this study, the prevalence of abdominal obesity was found higher $(85.6 \%)$ than the prevalence reported by another study done in South Korea $(38.2 \%)^{23}$ Though this study was not comparable as the study was community-based. High prevalence in the present study may be due to differences in study design, a selection bias as people reporting to hospitals may have some or other conditions which may have had obesity at the background of their illness. However, the possibility of overestimation due to methodological error is very minimal because of the use of standardized instruments and trained personnel. The literature search revealed several reports of obesity based on inpatients but only one based on outpatient attendance.

This study found $86.3 \%$ prevalence of abdominal obesity among women and $84.5 \%$ among men. This finding is higher than the prevalence found in South Korea (male $=46.2 \%$ and female $=52.2 \%$ ). ${ }^{23}$ The prevalence of abdominal obesity is also higher than other studies done in Slovak Republic (male $=54.2 \%$, female $=35.0 \%$ ) and in India $(51.9 \%) .{ }^{24,25}$ Higher abdominal obesity among women in this study may be because women (over $55.0 \%$ ) have accumulated excess fat before 45 years of age. It is known that abdominal obesity may increase substantially with each pregnancy independent of total body fat ${ }^{26}$ which may explain higher obesity among women of childbearing age.

Recognizing the importance of abdominal obesity as a risk factor for many diseases conditions, we initiated this study because hospitals attract a large number of people such as patients, their escorts, and staff under one roof which allows screening of a huge number of people at little extra time and cost. Additionally, there is a captive population in the hospitals where service seekers are more amenable to the advice given by health workers. The other objective is to highlight how health systems are missing opportunities for diagnosis of obesity which has a profound impact on health.

As this is a hospital-based descriptive single-center study done using retrospective record review, the obesity estimation may be higher.

\section{CONCLUSIONS}

The prevalence of obesity among hospital outpatients in our study is higher than other community-based studies, seriously signals the need for the health system leaders to formulate actions to detect and intervene before it develops into overt NCDs. Hospitals also provide great opportunities for health promotion to a receptive and concerned population. Therefore, we recommend to the Government of Nepal to introduce screening for obesity using $\mathrm{WHtR}$ at the first point of contact with the health system as well as during STEPS surveys as a superior metric and set up interventions in a phased manner to stem the rising tide of NCDs.

\section{ACKNOWLEDGEMENTS}

We would like to acknowledge the management of BP Eye Foundation, Hospital for Children, Eye, ENT and Rehabilitation Services for permission to conduct and report the study.

\section{Conflict of Interest: None.}

\section{REFERENCES}

1. Magriplis E, Andreou E, Zampelas A. Nutrition in the Prevention and Treatment of Abdominal Obesity. 2nd ed. In: Watson RR. Amsterdam (NL): Elsevier Science; 2018. Chapter 21, The Mediterranean Diet: What It Is and Its Effect on Abdominal Obesity; p. 281-99. Available from: https:// books.google.com.np/books?id=MzV8DwAAQBAJ\&dq. [Full Text]
2. $\mathrm{Ng} \mathrm{M}$, Fleming $\mathrm{T}$, Robinson $\mathrm{M}$, Thomson B, Graetz $\mathrm{N}$, Margono C, et al. Global, regional, and national prevalence of overweight and obesity in children and adults during 1980-2013: a systematic analysis for the Global Burden of Disease Study 2013. Lancet. 2014 Aug 30;384(9945):766-81. [PubMed | Full Text | DOI] 
3. Popkin BM. The world is fat. Sci Am. 2007 Sep;297(3):88-95. [PubMed | Full Text | DOI]

4. NCD Risk Factor Collaboration (NCD-RisC). Trends in adult body-mass index in 200 countries from 1975 to 2014: a pooled analysis of 1698 population-based measurement studies with $19 \cdot 2$ million participants. Lancet. 2016 Apr 2;387(10026):1377-96. [PubMed | Full Text | DOI]

5. Popkin BM, Doak CM. The obesity epidemic is a worldwide phenomenon. Nutr Rev. 1998 Apr;56(4 Pt 1):106-14. [P | Full Text | DOI]

6. Vaidya A, Shakya S, Krettek A. Obesity prevalence in Nepal: public health challenges in a low-income nation during an alarming worldwide trend. Int J Environ Res Public Health. 2010 Jun;7(6):2726-44. [PubMed | Full Text | DOI]

7. Ministry of Health. Nepal Demographic and Health Survey 2016 [Internet]. Kathmandu (NP): Ministry of Health; 2017 Nov [cited 2021 Dec 29]. Available from: https://www. dhsprogram.com/pubs/pdf/fr336/fr336.pdf. [Full Text]

8. Nepal Health Research Council. Non Communicable Diseases Risk Factors Survey 2007/08 [Internet]. Kathmandu (NP): Nepal Health Research Council; 2008 [cited 2021 Dec 29]. Available from: http://library.nhrc.gov.np:8080/nhrc/ handle/123456789/147. [Full Text]

9. Nepal Health Research Council. Non Communicable Diseases Risk Factors: STEPS Survey Nepal 2013 [Internet]. Kathmandu (NP): Nepal Health Research Council; 2013 [cited 2021 Dec 29]. Available from: https://www.researchgate. net/publication/262830102_Non_Communicable_ Diseases_Risk_Factors_STEPS_Survey_Nepal_2013. [ [ Full Text]

10. Dhimal M, Bista B, Bhattarai S, Dixit LP, Hyder KA, Agrawal N, et al. Report of Non Communicable Disease Risk Factors: STEPS Survey Nepal 2019 [Internet]. Kathmandu (NP): Nepal Health Research Council (NHRC); 2020 [cited 2021 Dec 29]. Available from: http://nhrc.gov.np/ wp-content/uploads/2020/04/NEPAL\%E2\%80\%93Noncommunicable-disease-risk-factors-STEPS-Survey-2019-\%E2\%80\%93-Tobacco-Factsheet.pdf. [․ull Text]

11. Subedi YP, Marais D, Newlands D. Where is Nepal in the nutrition transition? Asia Pac J Clin Nutr. 2017 Mar;26(2):358-67. [PubMed | Full Text | DOI]

12. Nepal Health Research Council, MoHP, Monitoring Evaluation and Operational Research. Nepal Burden of Disease 2017: A country Report based on the Global Burden of Disease 2017 Study [Internet]. Kathmandu (NP): NHRC, MoHP, and MEOR; 2019 [cited 2021 Dec 29]. Available from:http://nhrc.gov.np/wp-content/uploads/2019/04/ NBoD-2017_NHRC-MoHP.pdf . [Full Text]

13. Nepal Health Research Council (NHRC). Assessment of Burden of Disease in Nepal 2009 [Internet]. Kathmandu (NP): Nepal Health Research Council (NHRC); 2018 [cited 2021 Dec 29]. Available from: http://nhrc.gov.np/ wp-content/uploads/2018/02/Assessment_of_Burden_of_ Disease_in_Nepal_2009_opt.pdf. [피ll Text]

14. World Health Organization. Waist Circumference and Waist-Hip Ratio: report of WHO expert consultation [Internet]. Geneva $(\mathrm{CH})$ : World Health Organization; 2008
Dec 8-11 [cited 2021 Dec 28]. Available from: https:/ / www. who.int/publications/i/item/9789241501491. [Full Text]

15. Ashwell M, Gunn P, Gibson S. Waist-to-height ratio is a better screening tool than waist circumference and BMI for adult cardiometabolic risk factors: systematic review and meta-analysis. Obes Rev. 2012 Mar;13(3):275-86. [․ Full Text | DOI]

16. Ashwell M, Hsieh SD. Six reasons why the waist-to-height ratio is a rapid and effective global indicator for health risks of obesity and how its use could simplify the international public health message on obesity. Int J Food Sci Nutr. 2005 Aug;56(5):303-7. [․ㅏbMed | Full Text | DOI]

17. Shrestha R, Upadhyay SK, Khatri B, Bhattarai JR, Kayastha M, Upadhyay MP. BMI, waist to height ratio and waist circumference as a screening tool for hypertension in hospital outpatients: a cross-sectional, non-inferiority study. BMJ Open. 2021 Nov 25;11(11):e050096. [PubMed | Full Text I DOI]

18. Jayawardana R, Ranasinghe P, Sheriff MH, Matthews DR, Katulanda P. Waist to height ratio: a better anthropometric marker of diabetes and cardio-metabolic risks in South Asian adults. Diabetes Res Clin Pract. 2013 Mar;99(3):292-9. [PubMed | Full Text | DOI]

19. Dilip Malshe S, Anand Udipi S. Waist-to-Height Ratio in Indian Women: Comparison With Traditional Indices of Obesity, Association With Inflammatory Biomarkers and Lipid Profile. Asia Pac J Public Health. 2017 Jul;29(5):411-21. [PubMed | Full Text | DOI]

20. Prasad DS, Kabir Z, Suganthy JP, Dash AK, Das BC. Appropriate anthropometric indices to identify cardiometabolic risk in South Asians. WHO South East Asia J Public Health. 2013 Jul-Dec;2(3):142-8. [PubMed | Full Text I DOI]

21. Vikram NK, Latifi AN, Misra A, Luthra K, Bhatt SP, Guleria $\mathrm{R}$, et al. Waist-to-Height Ratio Compared to Standard Obesity Measures as Predictor of Cardiometabolic Risk Factors in Asian Indians in North India. Metab Syndr Relat Disord. 2016 Dec;14(10):492-9. [릴ed | Full Text | DOI]

22. Murugan R, Therese M. Prevalence and associated factors of obesity among adults in Tamil Nadu state, South India. International Journal of Current Research. 2016 Sep;8(09):38193-200. [Full Text]

23. Lee O, Lee DC, Lee S, Kim YS. Associations between Physical Activity and Obesity Defined by Waist-To-Height Ratio and Body Mass Index in the Korean Population. PLoS One. 2016 Jul 22;11(7):e0158245. [PubMed | Full Text | DOI]

24. Csongova M, Volkovova K, Gajdos M, Gurecka R, Koborova I, Liskova A, et al. Gender-associated differences in the prevalence of central obesity using waist circumference and waist-to-height ratio, and that of general obesity, in Slovak adults. Cent Eur J Public Health. 2018 Sep;26(3):228-33. [PubMed | Full Text | DOI]

25. Dilip Malshe S, Anand Udipi S. Waist-to-Height Ratio in Indian Women: Comparison With Traditional Indices of Obesity, Association With Inflammatory Biomarkers and Lipid Profile. Asia Pac J Public Health. 2017 Jul;29(5):411-21. [PubMed | Full Text | DOI] 
Shrestha et al. Abdominal Obesity among Outpatients in a Tertiary Level Eye ENT Hospital: A Descriptive Cross-sectional study

26. Danilack VA, Brousseau EC, Phipps MG. The Effect of Gestational Weight Gain on Persistent Increase in Body Mass Index in Adolescents: A Longitudinal Study. J Womens
Health (Larchmt). 2018 Dec;27(12):1456-8. [PubMed | Full $\underline{\text { Text }} \mid \underline{\mathrm{DOI}}]$

This work is licensed under a Creative Commons Attribution 4.0 International License. The images or other third party material in this article are included in the article's Creative Commons license, unless indicated otherwise in the credit line; if the material is not included under the Creative Commons license, users will need to obtain permission from the license holder to reproduce the material. To view a copy of this license, visit http://creativecommons.org/licenses/by/4.0/ 